県立萩高校蔵英学資料目録

資料 III

\title{
県立萩高校蔵英学資料目録
}

\section{- LIST OF ENGLISH BOOKS BELONGED TO THE HAGI SENIOR HIGH SCHOOL (YAMAGUTI-KEN, HAGI CITY)}

1. Macaulay. Thomas Babingtan : The history of England. 3 Vols. Leipzig, 1849. $15.5 / 11 \mathrm{~cm}$.

2. Landmann, Isaac, F. A. S. : The principles of fortification, for the use of the Royal Military Academy, at Wolwich. London, 1853.60p/2pl. $23 / 14 \mathrm{~cm}$. K.

3. Hodge, Thomas : Catechism of fortification, 2nd Ed. London, 1855. 48/32pp. $17.7 / 11 \mathrm{~cm}$.

4. The Holy Bible. New York, 1858. 835/260pp.

5. Wilson, Marcius : The readers of the school and family series, II, III, IV, readers. 154/264/360p. New York, d. u. (1,11) IV-1860 19/12.5cm.

6. Douglas, General Sir Howard Bart : A treatise on naval gunnery. London, 1860 . $668 \mathrm{p}$, P1. 2. $23 / 14 \mathrm{~cm}$. K.

7. Vauban : First system of fortification; preceded a life of Vauban. 3rd Ed. $56 \mathrm{p} / 1$ p1. $23 / 14.5 \mathrm{~cm}$. K.

8. Griffiths, Major $F$. A. : The artillerist's manual \& British soldiers compendium. London, 1862.375 p. $17 / 10.8 \mathrm{~cm}$.

9. Instructions for the exercise and service of great guns, etc., on board Her Majesty's ships. London, 1863. 152p. 13/9.8cm. K.

10. Robbins, Captain : The cavalry catechism. London, 1864. 200p. 18.2/10. $5 \mathrm{~cm} . \mathrm{K}$. 


$$
\text { 英 学 史 研 究 第 } 6 \text { 号 }
$$

11. Latham, R. G. : An elementary English grammar, for the use of schools. London, 1864. 224 p. $19 / 12.5 \mathrm{~cm}$. K.

12. Norie. W. : A complete epitome of practical navigation. London, 1864. 344/359pp. $23 / 14 \mathrm{~cm}$. K.

13. Navigation and nautical astronomy. Prepared for the use of U. S. Naval Academy. 2nd Ed. New York, 1865. 283p. 19.5/13cm.

14. Davies, Charles, LL. D. : Primary arithmetic. New York 1866. 107p. $16.4 / 10.7 \mathrm{~cm}$.

15. Kipling, Robert, N. A. : Elementary treatise on sails and sail-making; with draughting, and the centre of effort of the sails. London, 1866. 196p. $18 / 10.4 \mathrm{~cm}$. K.

16. Simon. Kerl, A. M. : A common-school grammar of the English language. New York, 1866. 350p. $1 \% / 12.3 \mathrm{~cm} . \mathrm{K}$.

17. Mill, John Stuart : On liberty. people's Ed. London, 1867. 63/32pp. 19. $6 / 13 \mathrm{~cm}$.

18. Cornell, S. S. : Cornell's high school geography. New York, 1867. 405p. $19.3 / 12 \mathrm{~cm}$.

19. Davies, Charles, LL. D. : School arithmetic, analitical and practical. Revised Ed. New York, 1867. 326p. 17.3/11.6cm.

20. Markham, Mrs. : A history of France. New \& revised Ed. London, 1869. 541p. $19 / 12 \mathrm{~cm}$.

21. Mill, John Stuart : Principle's of political economy with some of their applications to social philosophy. People's Ed. London, 1869. 591p. 19. $8 / 13 \mathrm{~cm}$.

22. Guy, Joseph : School geography, on a new and easy plan. London, 1869. 244p. $16 / 9.8 \mathrm{~cm}$.

23. Lennie, William : The principles of English grammar. London, 1869. 


\section{県立萩高校蔵英学資料目録}

180p. $14.5 / 9.2 \mathrm{~cm}$. M.-Meirinkan.

24. Quackenbos, G. P. : An English grammar. New York, 1871. 288p. $19 / 12.3 \mathrm{~cm}$.

25. William Smith, LL. D. : A smaller history of England. New York, 1871. 357p. $17.1 / 11 \mathrm{~cm}$.

26. Quackenbos, G. P. LL. D. : First book of English grammar. New York, 1871. 120 p. $16.3 / 10.4 \mathrm{~cm}$.

27. Quackenbos, G. P. LL. D. : Illustrated school history of the United States and the adjacent parts of America. New York, 1872. 516/xxiv/pp. $19.2 / 13 \mathrm{~cm}$.

28. Smith. Barnard, M. A. : Arithmetic for sehools. London, 1872. 347p. $12.8,12.3 \mathrm{~cm}$.

29. Quackenbos, G. P. LL. D. : Elementary history of the United States : with numerous illustrations and maps. New York, 1872. 230p. 17/11cm.

30. Mitchell, S. Augustus : The new primary geography : illustrated by twenty coloured maps. Phil., 1873. 100p. $22 / 18.5 \mathrm{~cm}$.

31. Mrs. Markham \& Eliza Robbins (with questions) : History of England. New York, 1873. 417p. $19 / 12.5 \mathrm{~cm}$.

32. Wayiand, Francis D. D. : The elements of political economy. Boston, 1873. 406 p. $20 / 13 \mathrm{~cm}$.

33. Peter Parley's Universal history. New York, 1874. 700p. 17.4/12.4cm.

34. Creasy, E. S., M. A. : The rise and progress of the English constitution. Revised and with additions. New York, 1875. 359p. 19/12.5cm.

35. Guizot, $M$. : General history of civilization, from the fall of the Roman empire to the French revolution. With notes by C.S. Henry, D. D. New York, 1875. 316p. 19/12cm.

36, Spencer, Herbert : Education : intellectual, moral, and physical, New 


\section{英 学 史 研 究 第 6 号}

York, 1875. 283p. 20.2/13cm.

37. Mill. John Stuart : On representative government, considerations. People's Ed. London, 1876. 141p. 19.3/12.5cm.

38. Quackenbos, G. P. LL. D. : Advanced course of composition and rhetoric : A series of practical lessons. New York, 1876. 454p. 19.1/12. $5 \mathrm{~cm}$.

39. Francis Wayland : Elements of intellectual philosophy. 20th Ed. New York, 1876. 419p. $19.2 / 13 \mathrm{~cm}$.

40. Mrs. Markham : A history of Germany, from its invasion by Marius down to the year 1867. London, 1872. 453p. $18.7 / 12 \mathrm{~cm}$.

41. Wilson, Marcius : History of the United States. New York, 1867. 459p. $19.3 / 12 \mathrm{~cm}$.

42. S. R. Brown, A. M. Rev. : Colloquial Japanese, or conversational sentences and dialogues in English and Japanese. Yokohama, 1862. 80p. $15.6 / 11.3 \mathrm{~cm}$.

43. : Japanese and English. 1884.

44. Van der Piji's gemeenzame leerwijs, voor degenen die de Engelsche taal..... Dordrecht, 1854. Nagedrukt te Nagasaki, Ansei 4e (1857). 192p. $20 / 13 \mathrm{~cm}$.

45. Murray, Lindley : English grammar. London, 1861. 328p.

46. Dinneo's analytical grammar of E. language. d. u. 214p.

47. Satow : Kaiwa Hen. Yokohama, 1873. (Signed by Chaimberlain)

48. The constitutional history of England. 4 vols. Oxford, 1903. (Donated by Kanai Risuke)

49. Suematsu Kenchô : A fantasy of Far Japan or Summer Dream Dialogues. London, 1905. (Name card of Baron Suematsu, Shiba, Tokyo; with Compliment from Queen Annes Mansion, St. James Park, S. W.) 
県立萩高校蔵英学資料目録

(Donated by Prince Yamagata Isaburô)

50. Swinton : English grammar. Reprinted in Japan. M. 18 (1885) Tokyo, Sanseido etc.

\section{二、邦 刊 (交) 本 之 部}

1 ウェンリート：和英商話

2 ボイル：英国史

3 石 橋 政 方：英 語箋

4 メリ・スイフト; 理学初歩 翻刻版

5 福 沢 諭 吉：西洋事情 3

6 足 立 梅 景：英吉利文典字類

7 開 成 所 : 英吉利文典 木版

(明 3 年版もあり)

8 片 山 淳之助 : 西洋衣食住 絵入

9 阿 部 友 之：捜訳英吉利文典

10 福 地 万世: 西史掔要 3

11 スミット・神田孟格訳：星学図説 2

12 塚 本 甫 明：筆算訓蒙 4

13 丁韓良・本山訓点：格物入門 (漢文) 7

14 河 津 孫四郎：西洋易知録 6

15 西 村 茂 樹：泰西史鑑 30

16 内 田 正 雄 : 興地誌略 9

17 石 黒 忠 惪 : 化学訓蒙 4

18 吉田賢輔-他：格物入門和解 16

19 鈴 木 弥 堅：華盛頓軍記 6

20 松岡 子 保 : 英単語篇増訳

21 松 岡 啓：幼童必読英学階梯
日 新 堂 文久 2

長門温知社 "

万延 2

和 新 館 慶応 2

尚古堂 "

伊月邸舎采

老皇 館 1 3

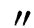

"I

開成学校 明治 2

中外堂 $\prime \prime$

沼津学校呐

明 親 館

知新館 $\| \sim 4$

大学南校明治 3

英蘭堂 "

北 門 社 "

宝集堂 "

京 都 " 4

好問堂 
英 学 史 研 究 第 6 号

22 中 村 正 直 : 西国立志編 11

静岡木下版

23 福 地 源一郎 : 会 社 弁

大蔵省 $" \prime$

24 村 松 良 肃：登高自卑

文林堂 $/ 15$

25 石 橋. 島一徳 : 改正増補英語箋 2

26 鈴 木 良 輔：養生新編 4

尚古堂 "

27 瓜生翼：測地略 4

文 部 省 $\quad$ " $\sim 7$

28 中 村 方三郎 : デビス・幾何用法 3

中外堂 $"$ 6

29 西 村 茂 樹 : ヘルツホルン・家中経済

30 福 沢 諭 吉 : 西洋事情 10

塾出版局

31

帳合之法 4

32 武 藤・塚 原：算海方針 2

萬 巻 楼

33 小 幡 篤次郎：英氏経済論 6

/ $6 \sim 9$

34 片 山 淳 吉 : 物理階梯 3

和歌山県 $\quad$ 7

35 福 沢 諭 吉: 文明論の概略 6

II 8

36 山 本・川 北：カットル幾何学原礎 9

文林 堂

37 文 部 省 : 馬耳蘇氏記簿法

甲

府

38 宇田川 準 一 : 物理全志 10

39 永 峯 秀 樹：ギゾ一欧羅巴文明史

奎章閣 明治10

40 福 沢 諭 吉：民間経済録

41 永 田 健 助：宝氏経済学 5

思 誠 館

"I

42 伊 藤 正 信 : カントル氏初学人身窮理 2

文部省

/I 14

43 拂 波土(英)：主権論

II 16

44 新 井 次 郎：代数学教本 2

中 外 堂

45

: 航海教授書 7

46 寧 静 学 人 : 假名付英学階梯 3

47 岸俊 雄 : 西洋算法開諸法

海軍兵学尞

慶応義 熟

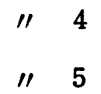

115 
県立萩高校蔵英学資料目録

48 西 村 茂 樹：農工世種家中経済 2

II 6

49 新 井 - 岸 : 代数学教授本 2

紀尾国屋

50 石

川：英学階梯 (假名付)

翰林堂 1872 